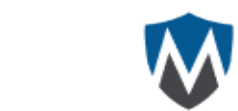

\title{
Main Steps of Doing Research and Development in Public Health
}

\section{Phongpisanu B*}

Sirindhorn College of Public Health Phitsanulok, Praboromarajchanok Institute of Health Workforce Development, Ministry of Public Health, Thailand

*Corresponding author: Phongpisanu Boonda, Sirindhorn College of Public Health Phitsanulok, Praboromarajchanok Institute of Health Workforce Development,

\section{Conceptual Paper}

Volume 2 Issue 6

Received Date: September 17, 2018

Published Date: November 08, 2018

DOI: $10.23880 /$ mjccs- 16000183

Ministry of Public Health, Thailand, Tel: +66 (0) 81 7859503; Fax: +66 (0) 55 313116; Email: phong2470@hotmail.com

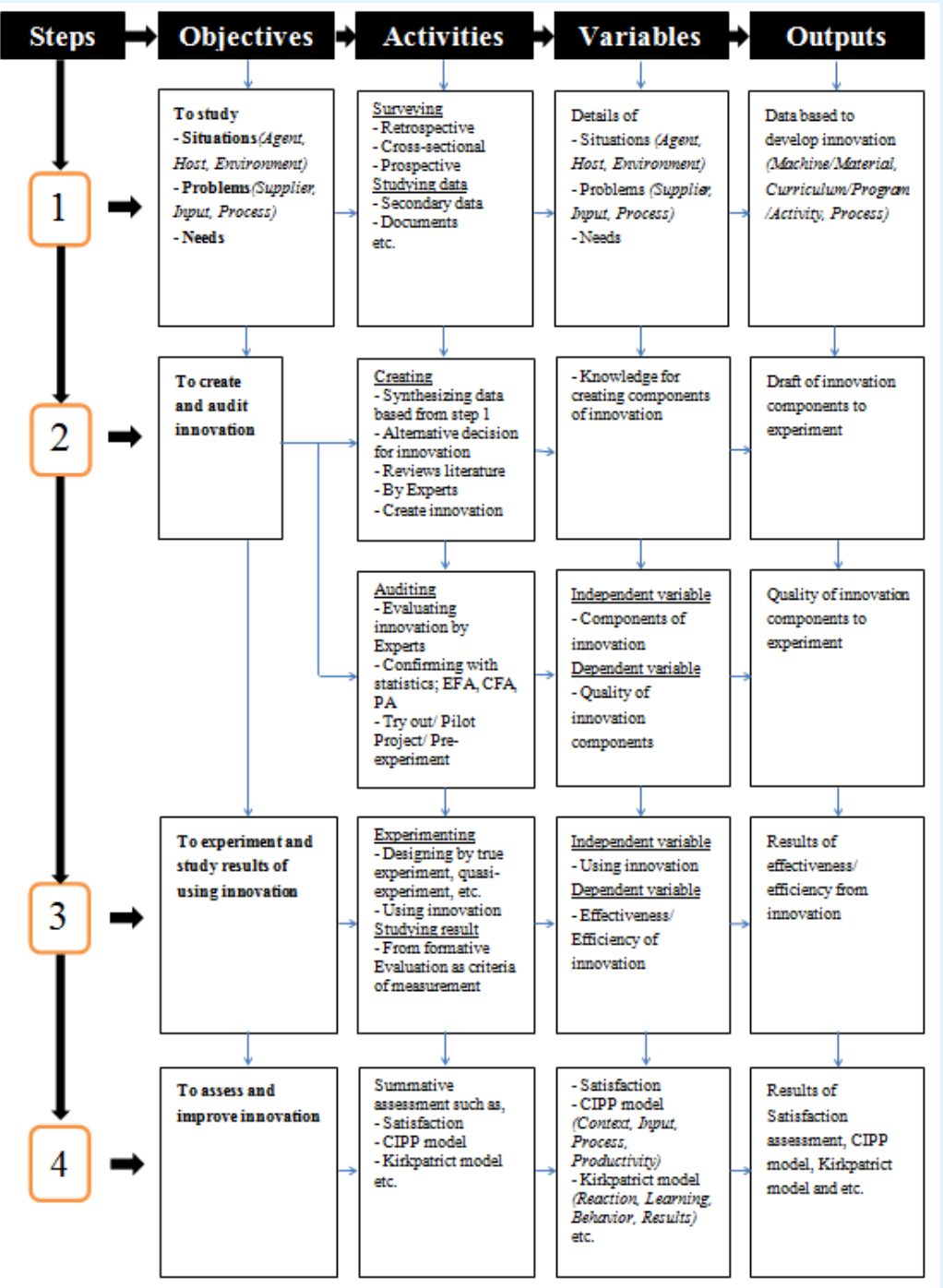

Figure 1: Main Steps of Doing Research and Development in Public Health. 


\section{Medical Journal of Clinical Trials \& Case Studies}

\section{Step 1: Studying Situations, Problems and Needs}

\section{Primary Data}

Survey about situations (agent, host, environment), problems, and needs their own work (health promotion, prevention, treatment, and rehabilitation of Communicable Diseases; CDs and Non-Communicable Diseases; NCDs) according to the PMQA [Leadership (LD), Strategy planning (SP), Customer and stakeholder (CS), Information technology (IT), Human resource (HR), Process management (PM), Result based management (RM)] and Six Building Blocks Plus (Service Delivery, Workforce, IT, Drug \& Equipment, Financing, Governance, and Participation), 7S (Structure, Style, System, Strategy, Staff, Skill, and Shared values), PESTLE (Policy, Economic, Social, Technology, Law, and Environment) from samples of population with 3 methodologies as follows: 1) Cohort study/ Prospective studies are the most trustworthy observational study, but like any observational study, they are subject to confounding, 2) Case control/Retrospective studies are often much more feasible, but potentially subject to recall bias and unrepresentative sampling, and 3) Cross sectional studies provide a quick snapshot of an association, but need to be interpreted with care.

\section{Secondary data}

Do the same with primary data from documents of office and/or other offices by using SWOT analysis then analyze the organization in the following two sections, 1) Using PESTLE for analyzing Opportunity and Threat; OT in the part of external organization, 2) Using 7S for analyzing Strength and Weakness; SW in the part of internal organization. After that use SIPOC Model for analyzing own works details. Write process or flowchart (one of five elements of SIPOC Model) their own work then use the team to brainstorm by using the multi-voting method to find the team's settlement. Problems will take place in 3 parts of SIPOC Model are SIP in part of OC are just monitor. When the problems have been analyzed then set priority the most important issues to determine the root causes with fishbone diagram to solve the root causes.

\section{Step 2: Creating and Auditing Innovation}

This conceptual model focused on doing research and development; R\&D that can lead to innovation and the innovations are 3 main types of mechanical/ material, curriculum/ program/ activity etc., and process. Creating innovation consisted of synthesizing data based from step 1 , alternative decision for innovation, reviews literature, by experts, and create innovation, In the part of auditing include consideration by evaluating innovation of experts, confirming with statistics; Exploratory Factor Analysis; EFA, Confirmatory Factor Analysis; CFA, and Path Analysis; PA, and try out/ pilot project/ pre-experiment. Independent variable is components of innovation and output is draft of innovation components to experiment. Dependent variable is quality of innovation components and output is quality of innovation components to experiment.

\section{Step 3: Experimenting and Studying Results of using Innovation}

Designing experimental research, there are 3 main types include 1) Pre- Experimental designs (not have samplings and comparisons), 2) Quasi- Experimental designs (not have samplings, but have comparisons), and 3) True- Experimental designs (have samplings and comparisons). There are several sub-types of experimental designs such as 1) design with minimal control: one-group pretest-posttest design; 2) design with rigorous control: randomized control-group pretestposttest design, randomized Solomon four-group design, randomized control-group posttest only design; 3) factorial design; 4) design with partial control: nonrandomized control-group pretest-posttest design, counterbalanced design, one-group time-series design, control-group time-series design.

Then study results from formative evaluation as criteria of measurement each experimental design. Independent variable is using innovation and dependent variable is effectiveness/ efficiency of innovation and output is results of effectiveness/ efficiency from innovation with formative assessment which delivers information during the implementation process, before the summative assessment. Both the assessors and the samples use formative assessment results to make decisions about actions. It is an ongoing, dynamic process that involves far more than frequent testing, and measurement of sample's action is just one of its components.

\section{Step 4: Assessing and Improving Innovation}

In summative assessment general, its results are used to make some sort of judgment, such as to determine 


\section{Medical Journal of Clinical Trials \& Case Studies}

what grade a sample will receive on an assignment, measure program effectiveness, or determine whether an organization has made adequate yearly progress. Summative assessment, sometimes referred to as assessment of acting, typically documents how much acting has occurred at a point in time; its purpose is to measure the level of sample, organization, or program success. Example, satisfaction assessment, assessment of kirkpatrict model (Reaction, Learning, Behavior, Results) in the case of training or human competency development, and assessment with CIPP model (Contexts, Inputs, Process, Productivities). 